\title{
CRYOGENIC DETECTORS OF PARTICLES: HOPES AND CHALLENGES'
}

\author{
Bernard Sadoulet. \\ Lawrence Berkeley Laboratory \\ University of Califormia \\ Berkeley, CA 94720
}

November 1987

Invited Talk at the IEEE Nuclear Symposiun

San Francisco, CA., October 21-23, 1987

\section{DISCLAIMER}

This report was prepared as an sccount of work sponsored by an arency of the United State Government. Neither the United State Government nor any azency thereof, nor any of their employees, makes any warranty, expres or implied, or esuumes mny kegal liability or responsibility for the sccuracy, completenea, or usefulneas of any information, apparatue product, or process disclosed, or reprewents that its use would not infringe privately owned rights. Reforence herein to any epecific commercial product, process, or service by trade name, Irademark, manufacturer, or otherwive does not necesarily conatitute or imply its endoraement, recommendation, of favoring by the United States Goverament or any azency thereof. The view and opinions of authors expreaned herein do not necesserily state or reflect those of the United Stutes Government or any agency thereod.

\footnotetext{
${ }^{1}$ This work was supported by the U.S. Department of Energy under Contract DE-ACO376SF00008
} 


\author{
Bemard Sadoulet \\ Deparinent of Physics \\ University of California \\ Berkeley, CA 94270
}

\section{Absiract}

We review the various methods proposed for cryogenic delection of particles, the current status of their development and their potential applications.

\section{Hasic Concepts}

Historically, particle detection has progressed through the use of quint of decrensing energy. In proportional chambers, paricle interactions with the gas produce electron-ion pairs with binding energies of typically $10 \mathrm{eV}$. Scintillation detectors involve excitation energies of rouglily $5 \mathrm{eV}$. Senticonductor ionization detectors rely on electron-hole pairs involving energies of the order of $1 \mathrm{eV}$, and this leitd to a very significant iniprovement in threshold and resolution. For instance, state of the ar silicon detectors of sinall dimensions reach th energy resolution of $100 \mathrm{eV}$ FWHM for $6 \mathrm{keV}$ X-ruys.

It seems therefore natural to uttempt to use quanta of even simaller energies: Croper pairs in a superconductor have binding energies of the order of $10^{-3} \mathrm{cV}$ and phonons in a crystal at $100 \mathrm{mK}$ have energies of $10^{-5} \mathrm{eV}$ (if they are thermalicied). Infrared astronomers have been using these facts for a long time. It is Niinikoski and Udo [1] who recognized in 1974 the potentialities of thermal methods for particle detection. The potentials of superconductivity have been recognized even earlier (1962 [2]). If efficient detection schemes using broken Cooper pairs ("quasiparticles") or phonons could be implemented, the large number of quanta involved could lead to very low threshoids and excellent resolution, on the order of one electron volt. In order to prevent thermal excitation of the quants to be detected, such detectors have to be maintained at very low temperature, typically much below one Kelvin, and are thus called cryogenic detectors.

Recent results show that these hopes are not totally unrealistic. In 1985 McCammon, Moseley, and coworkers [3] obtained a resolution of $100 \mathrm{eV}$ FWHM for a $6 \mathrm{keV}$ X-ray using a phonon detector and even more inupressively a baseline $F W: H M$ of $11 \mathrm{eV}$ indicating the possibilities of having a very low threshold. By decreasing the amount of energy trapped on impurities, they have achieved recently a resolution of $17 \mathrm{eV}$ FWHM (Fig. 1). (See their contribution at this conference (4]). Zehnder now oblains $50 \mathrm{eV}$ FWHM using quasiparticle detection in superconducting tunnel junctions (Fig. 2) [5].

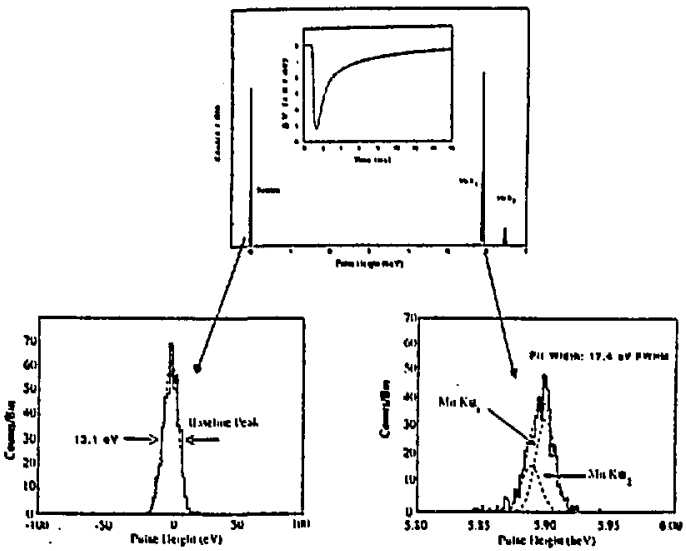

Fig. 1 Resolution obtained with a silicon calorimeter for $6 \mathrm{keV}$ $X$-rays (from [3]).

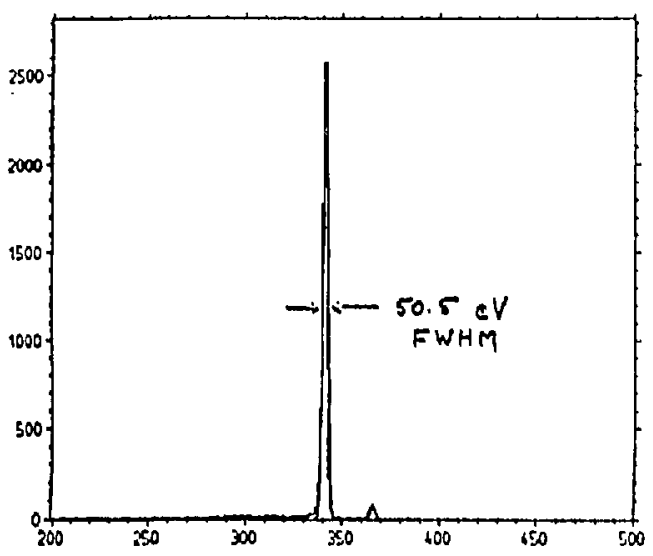

Fig. 2 Resolution obtained with a tin tunnel junction for $6 \mathrm{keV}$ $\mathrm{X}$-rays (from [5]).

\section{Rotantial Applications}

2.1 Interesting Pronertics. Cryogenic decectors have several interesting properties which make them particularly atractive:

a) Such detcctors are sensitive in the oulk and allow any material to be used. Present detectors have volumes of the order of $(100 \mu)^{3}$ but scaling laws ind!cate, as we will see in sections 3 and 4 , that masses of tens of grams (even kilograms) may be reachicd. Therefore devices with large stopping power and high density could potentially be built for neutrons and gammia rity detection. This is also very interesting for rare processes (neutrino and dark matter particle scattering).

In some schemes (superconducting granules, baltistic phonon detectors), this volume sensitivity is nicely complemented by position resolution, an important property for imaging and background rejection. Submillimeter position resolution has been demonstrated by granules [6].

b) Yery low thresholds can be reached. The (tiny) $X$ ray detector of the Goddard-Wisconsin group $[3,4]$ could be operated with a threshold of $20 \mathrm{eV}$. If the Debye Law remains valid it very low temperature, similar thresholds may be possible at 15 mK with 10 to $100 \mathrm{~g}$ of (high Debye temperature) materials.

c) Hiah resolution may be possible as demonstrated by the results quoted above. This is more demanding than getting low threshold because, in addition to having quania of low enough energy to decrease statistical fluctuations, high resolution requires very low trapping of the energy into undetectable states.

d) Finally, cryogenic detectors may allow for the first time an unambiquous simnature [7] that the energy is released by a recoiling nucleus of low encrgy. Below a few $100 \mathrm{keV}$ of kinetic energy, the ionization yield is much smaller for a recoiling nucleus than for a recoiling electron with the same kinetic energy. Simultaneous measurement of ionization and heat deposition may allow discrimination between the iwo events. This may be important for background rejection in dark matter searches and in some nuclear physics experiments.

\subsection{Anplicalions}

Such properties are quite attractive for many purposes and explain why many groups are now engaged in the development of cryogenic detectors (Table l). Let us list some applications. 
2.2.1 In particle physics [8], thresholds below $1 \mathrm{keV}$ would allow the study of coherent scattering of neutrinos [9]. The high acsuracy which may be reached, for instance with supcrconductors, may be essential for progress in neutrinoless double beta decay $[10,8]$. Resolution may be interesting for the measurement of the electron neutrino mass. In tritium end point experiments, pile up problems exclude a simple measurement with a tritium implanted calorimeter [11]. However, cryogenic calorimetry nily be beneficial to a magnetic or electric separation scheme. The "BONUS" collaboration is interested in using calorinetry for a $v_{c}$ mass neasurement using the internal bremsstrahlung spectrum in the electron capture decay of 163110 [12].

2.2.2 In nuclear physics, excellent $x$-ray encrgy resolution obtuined with microcilorineters alreaty illows 113 ] much more deliziled study of levels llitg. 31. The low energy lliresholds may open the possibility of measuring mucleds recoil, L.g. in internal cipture of ${ }^{7} \mathrm{Bc} \rightarrow 7 \mathrm{~h}$. where the recoil energy is $40 \mathrm{oV}$. Wiuld resolutiony suectroscony ma sllow hoth all accurille mapping of the level struclure alld, combined with fursition resolution, is measurement by Doppler shift of the diresion of necleat revoil, importane for instanct in nuclear magnetism experimedus. lintilly. eryogenic technigues conld be used in high resolution newlecie devestion with high efficiency and position resolution.

2.2.3 In astrophysies, many groups are interested in

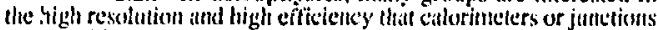
Lin provide for $1.10 \mathrm{keV} X$-ralys, liniging is in principle feasible with stveral detector elements or by pulse division. Anenter important application is the detection of weakly interating massive particles which may constitute tha dask component of the universe $|14,8,7,15|$. These delectors must hatve targets of several kilograms, thresholds of a lew $100 \mathrm{eV}$, and very low raddoatclive batkgrounds. Even more demamding is the detection of solar neutrinos by coherent seattering $\{9\}$, or through the indium reiction $[16,17]$, where I ton defectors are necessary.
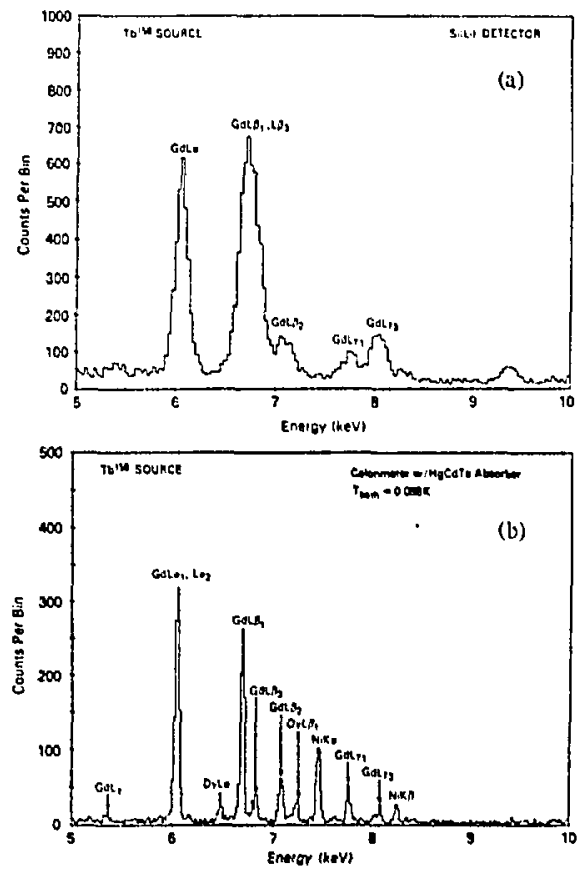

Fig. 3 Inprovement in resolution on $\mathrm{Tb}^{158}$ source (from [12]).

a) Spectrum obtained with Conventional silicon ionization detector

b) Spectrum obtained with a $35 \mathrm{eV}$ FWHM silicon calorimeter
2.2.4 Other Scientific ficlds. The accurate sinultaneous meisurement of encrgy and position may find applications in $x-r j y$ diffration sludies in material seience and biology, especially when low fluxes have to the used. A demonstration of high position resolution in the delection of ullatcold neutrons $|18 \mathrm{~g}|$ would open new possibilities in solid state physics.

2.2 .5 Industrial and Medical Apjlicitions, It is

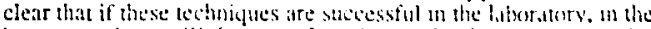
long run they will be transferred to the industry, e.p. tor nondestructive quality control, or to the hospital for $x$-ray and $r$-raty imaging. Cranules are already used at an experimental vage in industry $\{6\}$

it is importane however when revienme stibh a list not to

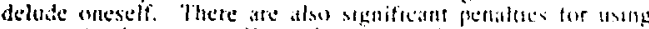

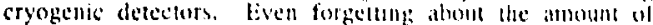

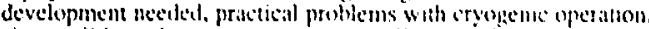

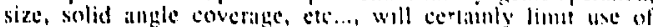

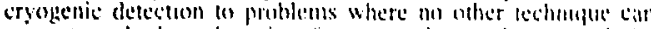

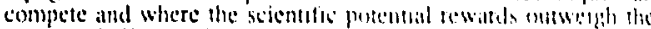
amount of effort needed

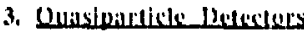

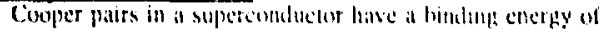

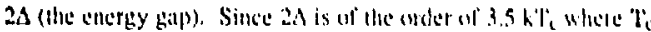

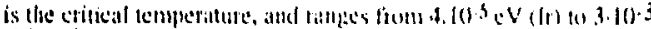
(Nb), the defosition of evell a modest atmoum of energy in a superconduclor leids to a large numbet ol botken cisplet patits

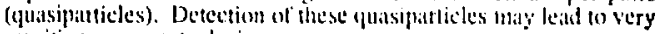
sensitive or alceurate devices.

\subsection{Broikine of Sunuroudestivity}

One way to detect guasiparticle is to make a detector element small enough for the superionductivity to be busen by the energy depossion.

3.1.1 Superheated Supereonductiog Granules. As proposed originally by a Orsily groul [19], latter joined by

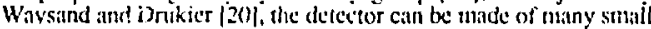
spheres of a few microns diameler. If they are immersed in a magnetic field, the eransition of a single sphere from the superconducting to the nomill state ean be detected through the suppression of the Meissner effect and the variation of magnetue flux in a loop surrounding the spleres (Fig. 4 and 5). Position resolution may be obtained with crossed loops or by comparing the Mux variation in separaled loups ("flux division"). a particles ate relatively easily detected by spheres of $6(0 \mu$ dianeter and detection of $X$-rays of fll keV have been reported with spheres of 10.1512 . Gramles of $3 \mu$ are sensitive to mininum ionization particles $[20]$ follows

The main teclmologicil problems may be summirized as

i) Manufacturing of regular enough spleses [21]. In addition to the obvaus dependence of the heat capacity of spheres on the cube of their ratius, there may be variation of seessitivity due to the internal structure and the orientation of the gritins [22]. Interaction between grains may also change their sensitivity as their selative distance nuciuates

With current, adtuiticdly crude, methods, a large number of granules seem to be insensitive, lealding to low overa!l guatum efficiency even though high efficiency has been clained for the sensitive grains $\{23\}$. But rapid progress in manufacturing and packaging is claimed by some of the groups involved $\mid 21\}$.

b) The strisitivity of the amplifier attached to the loop is also a problem for very small sphercs, since the flux change goes as the cube of the radius. Two directions are being explored: The use of (RI) SQUID's, which hive been demonstrated by the University of British Columbia group [23]. and the measurement of the derivative of the Dux variation with respect to time which goes at the square of the radius $\mid[6]$.

Overall, alihough spheres of very small diameter can obviously be made very sensitive, this method appears (at least to this reviewer) unlikely to achieve very low thresholds in a consistent way. Its resolution at low energy will always be poor since the cnergy measurement relies on the number of spheres which are driven normal. But the schene may have advantages in specific siluations: 


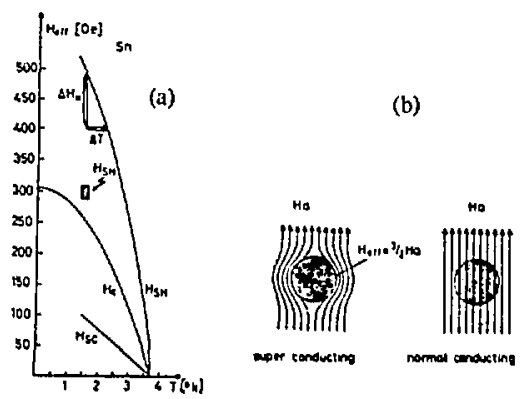

Fig. 4 a) Phase diagram of Sr granules. $\mathrm{HI}_{\text {sh }}=$ super heating field $B_{S c}=$ super cooling field $\mathrm{H}_{\mathrm{c}}$ - critical thennodynamic field

b) Meissner effect (from Ref. [22]).

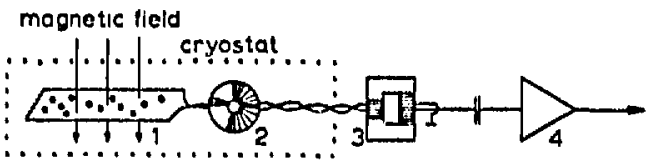

Fig. 5 Detection of superconducting-normal transition with a sensing loop (from [30]).
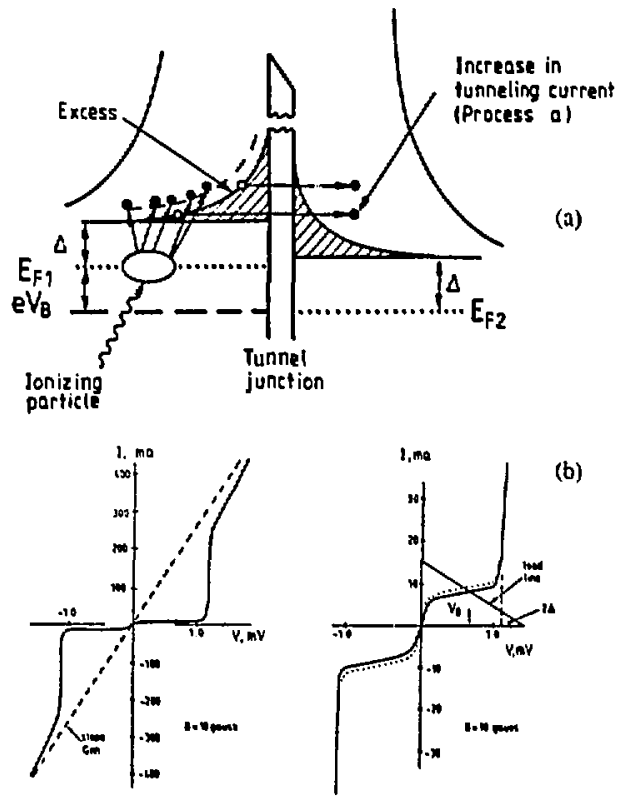

Fig. 6 Principle of tunnel junction operation (from [16]). a) Level diagram

h) IV curve a) Position resolution of 0.5 millimeter have already been achieved on industrial imaging devices [6] and the use of thux division with DC SQUID's may allow to reach a few tens of microns [18]. This could be extremely interesting for $X$-riay crystallography and industrial and medical inaging (positron emission tomography). Range may also be measured by the number of normal spheres, which together with position mensurenent may bring some discrimination power against background for the detection of rare processes

b) East timing is presumably possible.

c) The device could be mide insensitive to minimum ionization deposition. This may be interesting for transition radiation [2I].

d) The metastability of these granules (in most configurations) prevents them from recovering when they have teen struck, giving a built-in memory which can be reat out after the fact, c.g. by flipping hack the gramules, Together with the natural radiation hitrdness, this may be interesting in specifie high rate applications.

3.1.2 Superconducting Fïm Methods. Vitrittions of the alove method which use silpereonducting film have heen suggested $|2,24,25|$. 'They mily allow one to use well developed lithogrtphic technitues to solve the problems of siac and position variability,

In addition to the magnetic methods deseribed for the granules, it is possible to detest the breaking of supereonductivity clectrictily by the variation of the resistunce of at thin and natrow supereonduetive film, when a small section of il le'comes normal. As reporled by Neuhattser at this conference $|26|$, the Stanford group has tested this sclieme. "They operate their film below the transition (in contrast to transition edge thernistors (see below) which are usually biased on the center of the transition). This nethod nuy be pronising because of its approximate linearity in the energy density deposited in the superconductor (above a certuin threshold).

\subsection{Tunnalline of Ounsinarlicles}

A potentially much more sensitive and accurate nethod of detecting quasiparticles is to make them tunnel through an insulating bartier between iwo superconductors (SIS). Fig. 6 slow the level diagram and the I $V$ characteristics of a tunnel junction.

The absorber is made of a superconductor cooled down in such a wily so as to mininize fornation of magnetic vertices and maintained at low enough temperature for the quasiparticles to be very long lived $\left(t \sim e^{-\Delta / k T}\right.$ ). In that way, the quasiparticles can diffuse through the nuedium (at velocity of a few $10^{6} \mathrm{nl} / \mathrm{s}$ ) and nake the many attempts ( $10^{6}$ or so) which are necessary for them to finally tunnel. The junction is typically biased below $2 \mathcal{L} / \mathrm{c}$ (typically at $V=\frac{\Delta}{e}$ ) so that it is in the off statc. A mugnetic field parallel to the junction suppresses the Josephson tunnelling of Cooper pairs. The quasiparicles liberaled by the initial interaction and tunnelling dhrough the junction will genernte an additional current.

After the pionecring work of Wood and White $|27|$, of Kuratado and Nazaki [28], and of Barone and coworkers [29]. recently very cncouriging results have been obtained by Twerenbold and Zehnder at SIN [30] and the von Felitzch group in

Munich [31,32]. Over the past year, Zehnder has succeded in decreasing the diffusion of quasiparticles along the connecting electrodes (essentially by decteasing their section) and has been able to obtain $37 \mathrm{cV}$ FWHM resolution with a $(50 \mu)^{2}$ junction with a $\$ 5 F$ source. (cf Fig. Ib which was obtained with a slightly worse junction) [5].

Many teams are now investigating these devices. Although photo-lithographic techniques may be used very effectively for the manufacturing, outstanding problenis still have to be solved.

a) The manufaciuring of low leakare junctions. Many junctions have a poorly understood leakage current in addition to the normal tunnelting of thermally excited quasiparticles (which disappears exponentially when the temperature is lowered). This does not seem to be due only to "microshorts", and the granularity of the tin film used by Zehnder may be responsible for the good performance of his junctions. Till now, this manufacturing process remains to a large exient "black magic". 
It is also very imponant for the junctions to be robust enough iu stand many cool-downs. This has been, for instance, the main problem of the Oxfurd group when they attempted to make junctions on indium (for their solar neutrino project) [16]. Recently, they made a significart breakthrough by building the junctions first on a niobium substrate and then growing the indium crystal on top.

b) Another significant problem is to collect quasiparticles created in a large volume. If the junction attached is small (siy $(50 \mu)^{2}$ for a cute of $1 \mathrm{~cm}^{3}$ ), quasiparticles will bounce against the butrier very seldom and nay get absorbed before having a chince to tunnel. Such devices would be very slow. Increasing the size of the junction (to $1 \mathrm{~cm}^{2}$ ) leads to an unacceptable increase of the noise due to the leakage current. A promising solution has been proposed by Booth [33]. If a sinall piece of superconductor of lower gip is attiched to the original superconducting crystal (Fig. 7), it will (rap efficiently quasipanticles in a much smaller volune. If the junetion is construcied on the lower gap superconductor, the tunnelling tinie should be decreased significantly. Zehnder recently demonstrated [5] this mechanism in a very specticular fashion, Covering a $0.15 \mu$ thick tin junction with $0.4 \mu$ of lead, he observed a

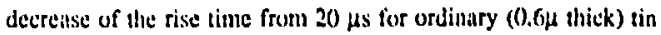
junctions down to $0.5 \mu$ s (fijg. 8). However, for reasons not yet understood, the Min lines from a iron 55 surce were completely wushed out.

\section{Hhonum Delucturs}

We now turn to the detection of phonons which represent even stmaller quanta of energy.

\subsection{Cilorimatry}

Onc of the oldest methods for detecting encrgy is calorimetry, where the temperature rise $\Delta \mathrm{T}^{\prime}$ resulting from the energy $\Delta \mathrm{E}$ absorbed is ,neasured

$$
\Delta \mathrm{T}=\frac{\Delta \mathrm{E}}{\mathrm{C}},
$$

where $C$ is the heat capacity. If this is done at low enough temperature for $\mathrm{C}$ to be very snall, the method can be in principle very sensitive. This is a detector of thermalized phonons and, because of their discrete nature, the detector will experience thernal energy fluctuations

$$
\delta E_{t h}=\sqrt{k T^{2} \mathrm{C}}
$$

This classicul tesult of thermodynanics can be derived by computing the fluctuations in number and individual energy of the boson phonon gas.

Jiv. (9) gives a schematic representation of a calorimeter designed for the detection of thermatized phonons. In order to allow a temperature rise to appear, the absorber has to be weakly linked to the heat bath. A smill thermistor (to limit its contribution to the heat capicity) is fixed to or implanted in the absorber and is biased under, say, a constant current $I$. If the resistance of the thermistor is $R$, any rise of temperature $\Delta T$ will give a change of voluge across is:

$$
\begin{aligned}
\Delta V & =\frac{\partial \mathrm{R}}{\partial \mathrm{T}} \| \Delta \mathrm{T} \\
& =\frac{\partial \mathrm{V}}{\partial \mathrm{T}} \Delta \mathrm{T} .
\end{aligned}
$$

If the conductance of the link is $G$, our energy pulse $\Delta E$ will appear as a sharp rise

$$
\Delta \mathrm{V}=\frac{\Delta \mathrm{E}}{\mathrm{C}} \frac{\partial \mathrm{V}}{\partial \mathrm{T}}
$$

followed by an exponential decay of time constant

$$
\tau=\frac{\mathrm{C}}{\mathbf{G}}
$$

(if we neglect clectro-thermai feedback [3])

The detector is fundamentally limited by the thermal fluctuations which, averaged over a bandwith $B$ would give an energy fluctuation

$$
\delta E=\frac{\sqrt{k T^{2} C}}{\sqrt{2 B \tau}}-\sqrt{k T^{2} C} \text { for } B \sim \frac{1}{\tau} .
$$

But on practical devices, we have to sake into account in addition
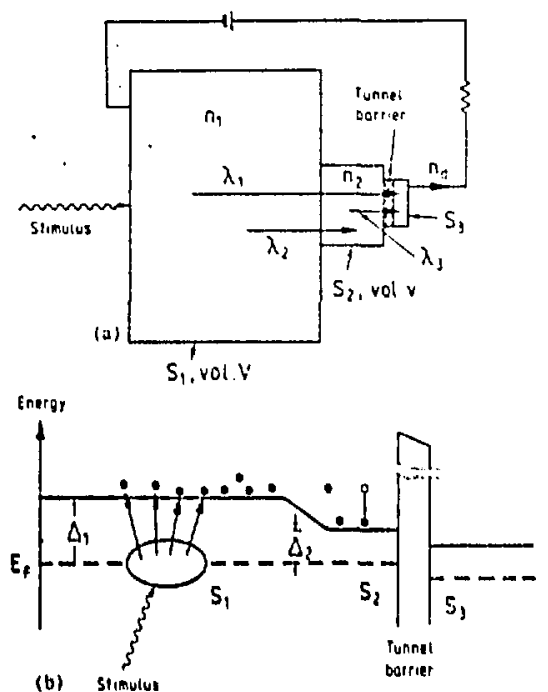

Fig. 7 Trapping of gutasiparticles below the jultetion ffrom (24)).

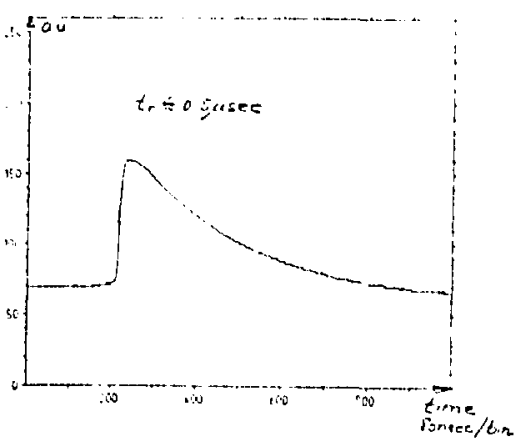

Fig. 8 Rise time obtained with a junction of $(50 \mu)^{2} \times(0.15 \mu)$ using trapping (from |5]).

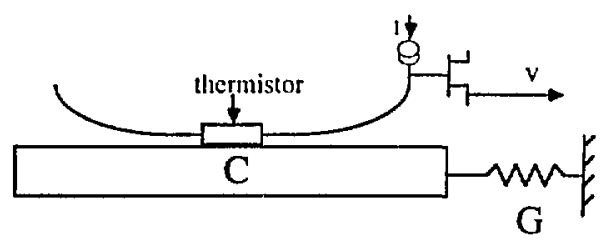

Fig. 9 Schematic representation of a calorimeter. 
- The Johnson noise.

- The amplificr noise.

- Any excess noise.

Standard optimum filtering methods $[34]$ give a final statistical uncertainty on the energy

$$
\delta E=\xi \sqrt{k T^{2} C} .
$$

At temperatures above $100 \mathrm{mK}$ the best thermistors investigated so far are doped semiconductors. They have large responsivity $\frac{\partial \mathrm{V}}{\partial \mathrm{T}}-1.5 \mathrm{~V} / \mathrm{K}$, the last two noise contributions are negligible and $\xi$ is of the order of 2 . Another sensor known, as a "transition edge thermistor", is investigated by Von Feilitzch and coworkers [31]. A thin superconducting film is operated at $T_{c}$ in the middle of its transition curve and its change of temperature measured by the change of resistance. Up to now, a detailed noise analysis has not been done.

4,1.1 Large Mass, Low Threshold Devices. The above formula indicates the obvious route for extrapolation to larger devices $[1,10,9]$. Since $C$ is proport mal to the mass, and for in insulator proportional to $\left(\frac{T}{T}\right)^{3}$ where $l_{i}$, is the Debye temperature.

$$
\delta \mathrm{E} \sim \mathrm{T}^{5 / 2} \mathrm{M}^{1 / 2}
$$

and a lirge augmentation in mass can in principle be compensuled by a noclest decreise in temperature. However, this relies on several assuinptions.

i) The heat capacity is indecd decreasing with the cube of the lemperature (the so called Debye Law). Impurities or surface effects mily beconie doninant. In addition, as explained in the next section, the concept of heat capacity at low temperature may be inadequate.

b) The responsivity $\frac{\partial V}{\partial T}$ should not decrease appreciably with temperature so that $\xi$ does not increase. If $\frac{\partial \mathrm{V}}{\partial \mathrm{T}}$ is too small, the energy noise $\delta E$ is dominated by the amplifier and Johnson noises and the scaling law given above is incorrect. $\delta \mathrm{E}$ becomes proportional to

$$
\frac{C}{\partial V} \sqrt{\tau}
$$

It is indeed the experience of many groups $[4,13,35]$ that as the temperature decreases, parasitic effects in semiconductors prevent them from being optimally biased as if they were an increasing thermal decoupling between electrons and phonons or $a$ increasingly strong field dependent resistance. Wang et al. [36] present at this conference the first evidence that an encouraging responsivity $\frac{\partial \mathrm{V}}{\partial \mathrm{T}} \sim$ $0.3 \mathrm{~V} / \mathrm{K}$ can be achieved with neutron transmutation doped germanium thernuistors [37] down to $20 \mathrm{nkK}$.

In order to see the potential significance of this result, let us imagine attached to such a sensor an absorber made of $50 \mathrm{~g}$ of boron. Even if no ballistic effect were present (see next section), their result would naively give a baseline fluctuation of $50 \mathrm{eV}$ FWHM. This assumes that one can maintain the same heat conductance as they measure now and that no significant excess noise is present. Such a detector would allow a serious search for low mass dark matter particles!

c) Finally, perhaps because of the decoupling between electrons and phonons, the semiconductor thennistors appear to be intrinsically slow at low temperature. Wang et al. [36] measured a time constant of $4 \mathrm{~ms}$ around $25 \mathrm{mK}$.

Therefore, in spite of recent progress, there are still significant problems for enlarging calorinteters operated at low temperature.

4.1.2 High Resolution Applications. A whole new set of problems arises when a high energy resolution device is needed (e.g. for X-ray application). In that case, it is less the baseline fluctuation than the absence of loss mechanism for the released encrgy, which is important. For instance, in a semiconductor lattice, ionization electrons or holes can be trapped in metastable states, locking in quanta of energy of the order of the gap. The Goddard-Wisconsin group [3] has given convincing evidence that this is the dominating effect in the disappointing tesolution they have first obrained with a silicon calorimeter. Switching to a low gap (but higher heat capacity) material. $\mathrm{Hg} \mathrm{Cd}$ Te, they have reached $17 \mathrm{eV}$ FWHM [4].

\section{4,2 Ballistic Phonons}

If sliould be noted, however, that very likily the picture outlined above is fundiunemally ineortect, since the lifetime of phonons of energy $E$ inside a cryslal goes as

$$
\tau=A(E)^{-5}
$$

where $E$ is measured in $K$ and $A$ is of the order of $1,(001) K^{5}$ for silicon [38]. So phonons originating from the interactum will skop thermalizing around $10 \mathrm{~K}$ unless special surfaces or inupurity effeces play a significant thermalizing role. Sucl. phontons are expected to be ballistic, that is to travel in straght thes and to bourse off surfaces. The concepes of temperitu. and lieill capatify are inadecjuate to describe such a sysicm.

This effect, first emplassized in this context hy Maris $|38|$ and Cabrera and coworkers $[39)$, is very well secen in experiments whene laser beams are used wo creite pliomons (sce, for instants. Wolte [38]). Several effecls observed in sintorimeters it low entherature (e.g. fist rise time with a 3.5 -inch silicon rod (30), eseiple of licat along silicon support structure 1131 , detection of a pulses in a transition edge delector irridiated ffom the busk of the wafer [25]) point to the existence of ballistic phonons. But up to now liese evidences were somewhat indirect. The Munich group [32] is reporting at this conference the first unambiguens evidence for the production of phonons of high enough energy for detection in aluninum tunnel junctions. Although their results on focussing properties and tinie propagation camnot readily be explained by a simple ballistic behaviour, this important paper illready shows the inadequacy of a thermalization nodel. Much nore quitntitative work is still needed in well defined geometry, to understind the share of energy deposited by a particle in ballistic phomons and the various diffusion and thermalization mechanisnis in a crystil. Reflections at surfaces and interfaces have also to be characterizel.

Instead of being a nuisance (38), ballistic phonons may ease the detection joh [39]:

a) Instead of the heat capacity of the glubal crystal, what counts now is the efficiency of energy collection $\varepsilon$ and the resolution $\delta \mathrm{E}_{s}$ of the sensor leiding to an accuracy in the deposited energies

$$
\delta \Delta E=\frac{\delta E_{s}}{E} .
$$

These detectors are more approprittely called acoustic delectors than calorimeters [39].

b) Because of the fast propagation, these plionons may allow a timing on several faces of the crystal (Fig.10: ). This requires a fast rise time of the sensor signal. In addition, focussing will occur and nay allow to loctilize the event within one millimeter by pulse division between several sensors [39]. Fig. I1 shows a Monte Carlo of the phonon distributicun on a $1 \mathrm{~kg}$ silicon cube.

These ideas are quite attractive. However, it remains to be proven that they can be inplenented. Two kinds of sensor can be envisaged.

a) Thermal ballistic phonon scnsors. In this case the sensor (Fig. 10b) is a large area thermistor such as that tested by Wang et al. [36]. The analysis-given in section 4.1.1 could be repeated, but taking now into account the efficiency $\varepsilon$ of coupling ballistic phonons to the sensor.

$$
\Delta \mathrm{E}=\frac{\xi}{\varepsilon} \sqrt{k \mathrm{~T}^{2} \mathrm{C}_{s}}
$$

where $\mathrm{C}_{s}$ is now the heal capacity of the sensor. This assumes that the large crystal is clamped solidly to the heat sink (without loosing phonons!). No measurement of e has been made yet. Ballistic phonons may like to couple to the impurity electrons or holes in the thermistors, so it could act as an efficient irap. However, problenss of transmission and thermalization at the interface between the absorber and the sensor may be important. 


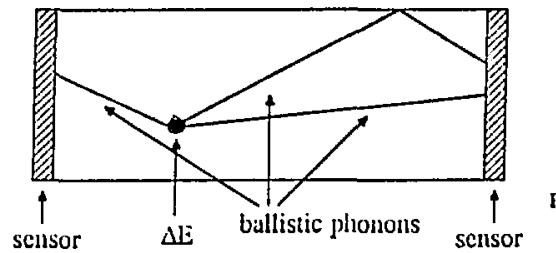

Figute 103

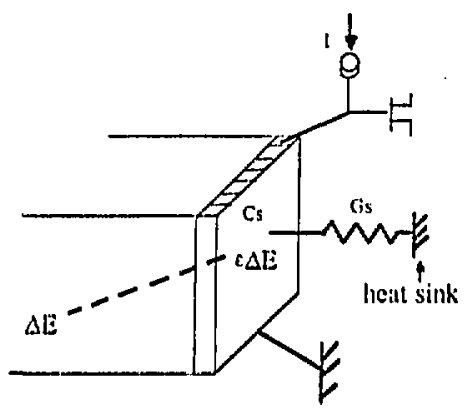

Figure 10b

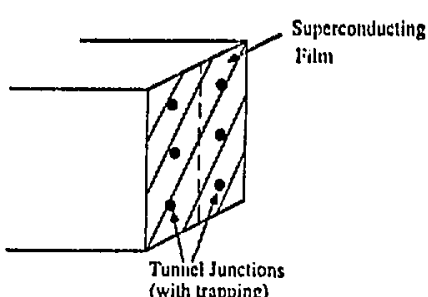

Figure 100

Fig. 10 Schematic representation of a ballistic phonon detector.

a) General view

b) Themal ballistic phonon sensor

c) Tunnel junction ballistic phonon sensor

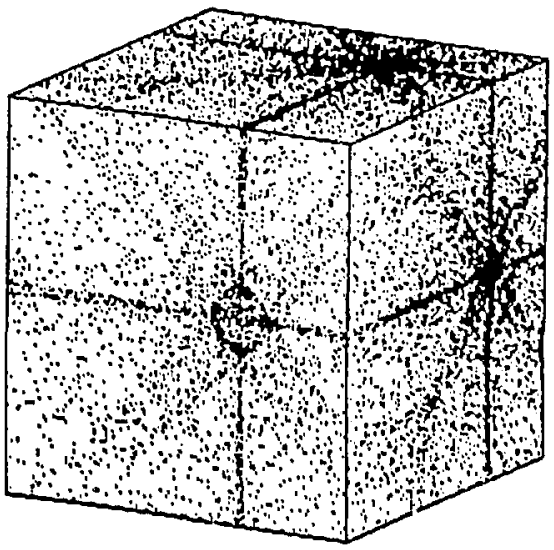

[7̈g. 11 Monte Cattlo of ballistic phonon propligantion in a $1 \mathrm{~kg}$ crystal of silicon (from |3 [\}).

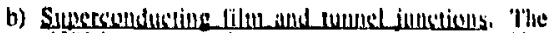
Stanford team $\mid 39$ ) has proponed to use a sunerconductive tim (Fig. 1(le) as a way to trip hallistic phomons, which ate energetic enough to break Comper pairs. The resulting clussipat!icles could then be trapped in the way described in section 3.2. below tunnel junctions (in a material of lower gap) and then detected. This scherne is quite elegant in the sense that the detector is insensitive to ihermalized phonons. It has been partially demonstrated experimentally by von Feilitzch and coworkers $|32|$ and by zehnder [5] This method involves, however, the developnent of relatively complex devices.

\section{Conclusion}

There is no lack of ideals in this new field of cryogenic detectors and some back of the envelope calculations give tantalizingly ligh sensitivity and resolutions. The expetinemal results are coming more slowly, as is natural in a field where the logistics (cryogenic technicues, low noise eleetronics) are not too easy. Some of them are guite encouraging, but is is clear that there is no lack of challenges cither!

Table I Cryogenic detcter devekpuments

\begin{tabular}{|c|c|c|}
\hline & Instilutions & Physics Interesis \\
\hline Mouxut Darcxilurs & & \\
\hline $\begin{array}{l}\text { Slc Canuwon, Moseley el } \\
{[3,4]} \\
\text { Silver et ad }(-10]\end{array}$ & $\begin{array}{l}\text { Wisconsin, Godkard } \\
\text { Liveniore, UC Deakeley } \\
\text { LBL, UC Irvine }\end{array}$ & $\begin{array}{l}\text { X Ray Astronomy } \\
\text { X Ray Astronomy }\end{array}$ \\
\hline Curta etal $[12]$ & $\begin{array}{l}\text { "Donus" Collab. } \\
\text { Mieudon, ClRN, Aahus, NYI }\end{array}$ & $110(163), \times$ Ray \\
\hline Niinikoski [\$1] & CERN & Neuvino \\
\hline Fiorini at al [14] & Milano & Dowble Beu \\
\hline Smith cial (14] & Rutherford, Imperial Coll. & Durk Maller \\
\hline Von Eeilitesch el al (3) & Munich: Technicsl University & Instrunientaion, Neuvinos \\
\hline Swoulctetat [3S] & LBLUUCDerkeley & Dark maker \\
\hline $\begin{array}{l}\text { Larou, Seidel, Alaris } \\
\text { [A2] }\end{array}$ & Brown University & Solar Neuvinot (rotons) \\
\hline Caluera et al [39] & Sunford, San Francisco Stale & $\begin{array}{l}\text { Coherent neuvinos } \\
\text { (Hallistic Phonons) }\end{array}$ \\
\hline
\end{tabular}

\begin{tabular}{|c|c|c|}
\hline & instıutuns & illystex Intciesls \\
\hline \multicolumn{3}{|l|}{ Supcroundiucling Gianiulas } \\
\hline Waysand et a [17] & Peris VIuColicge de liallice & Imagny Sulap newdinus \\
\hline Gonzales et a [31] & Anitiecy & Soly acuuilios, Dak Minlet \\
\hline Von Fisilitush el 2| |3|] & Munich: Technical Uiurcssll! & lisstrunkalativin, Neutrinos \\
\hline Preta, Skodolsky [22] & Munich; Max Hlanck Instilule & Culietent ne utrino scaitering \\
\hline Dnutier el d [23] & 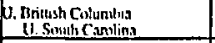 & Dak nislier, Duuble lies \\
\hline \multicolumn{3}{|l|}{ Supscronductinge Fins } \\
\hline Cubren et a [2S] & Stunlutt. Sun Francisto Stale & Insisumentation \\
\hline \multicolumn{3}{|l|}{ Tunnet Junctivess } \\
\hline Von Feilizach et d (3) & Muaich: Techutical Unwersity & Inscrunxentation, Neucrinos \\
\hline Zehnder [30] & $\sin$ & Neutrino, Instrumentation \\
\hline Twertnbold & LSA & Xray Asitonony \\
\hline Byone,Gray [29] & Napoli,Argonne & Instrumenitalion \\
\hline Booth [16] & Oxford & Solar neutrinos \\
\hline Bland & San Francisco State & Solar neuttinos \\
\hline
\end{tabular}


Acknowileduments

1 gratefully acknowledge enlightening discussions with $\mathbf{N}$. Booth, B. Cabrera, A. Coron, A. Drukier, F, von Fejlitzch, E. Haller, A. Linge, D. McCammon, H. Moseley, B. Neuhauser, T. Niinikoski, K. Pretzl, P. Richards, G. Seidel, E. Silver, G. Waysand, and A. Zehnder, in particular on many solid state physics, and instrumental aspects of the cryogenic detectors. I discussed with many other colleagues potential applications, in particular with D. Caldwell, E. Commins. E. Fiorini, R. Lanou, R. Ross, P. Smith, and H. Steiner.

This work is partially supported by the U.S. Departunent of Energy, contract

No. DE-AC03-765F00098.

\section{Beforences}

1. T.O.,Niinikoski and f.,Udo, "Cryogenic Detection of Neutrinos"?"Corn Preurin, N1' Report 74.6(1974)

2. N.K.,Sherman, Cill I. Phys,40,1).372(1962).

N.K., Sherman, Phys, Bey.Leil, 8, p.438(1962).

D.E.,Spiel and R.W.,Broom und E.C.,Critlenden, Bull.Am.l'lies, Sori,9,0.655(19)(14).

D.E.,Spicl and R.IV.,Brixom and E.C.,Critlenden,

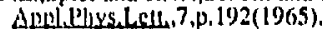

3. D.,McCimmonom," themal Deiectors for High Resolution

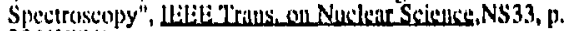
$236(1980)$.

D., MeCitmmon at al.,"Experimental 'Trst of a Sithgle-plioton Cillorimeter for X-Ray Specirosenpy".

Lappli, thys, 56(5),p.1263(1984).

4. S.II.,Moseley el al., "Advineses towird High Sipectral Resolution Quamtum X-ray Calorimetry",IEELE Nuclear Science Syniposium,San Francisco,(1987).

5. A.,Zendher, Talk at the APS worshop on cryogenic detectors, Rutgers University. Oct. 14 1987, and Private Communication.

6. G.,Waysand, IEEE Nuclear Symposium,San F.ancisto, (1987).

7. L.,Krauss and M.,Srednicki and F.,Wilczek,"Solar System Constraints on Diurk Matter Candidates", Phys. Rev.,D33,n.2079(1986).

B..Sadoulet," Prospects for detecting dark matter particles by elastic scattering", in Proceedings of the 13th Texas Symnosiam on Relativistic Astronhysics, Chicago,Dec1419,1986,Ulmer,M.L., Editor,(IVorld Scientific,Singapore),p.260(1987).

B.,Sidoulet,"Cryogenic Detection of Particles: Developinent Effor in The United States", in Proceedinus of the Workshon on Low lemperiture Detectors for Neutrinos and Dark Malter, Rigberg Castle, Tegemsee,March 1213,198, ,Pretzl, K, and Schnitz,N. andStodolsky,L., Edilors,(Springer-Verlag, Berlin,Heidelberg) p.86(1987) and references therein.

8. B.,Cabrera and D.O.,Caldwell and B.,Sadoulet,"Low temperature Detectors For Neutrino Experiments and DarkMatter Searches", in Proceedings of the 1986 Summer Sudy on the Physics of the Sunercondicting Supercollider,Snowmass, CO,June 23-July 11 1986, Donaldson, R, and Marx,J,, Editors.(DPF, American Physical Society, p. 704(1086).

9. A.K.,Drukier and L.,Stodolsky, Phys, Rey,D30, p.2205(1984)

B.,Cabrern and L.M.,Krauss and F.,Wilczek,"Bolometric Detection of Neutrinos", Plys, Rev, Lett, 55,p. 25(1985),

10. E.,Fiorini and T.O.,Niinikoski,"Low-temperature Calorimetry for Rare Decays", Nucl.Insir. Meth, 224,pp 8388(1984).

11. E.,Fiorini,"The Possible Imnact of Thernal Detectors in Nuclear and Subnuclear Physics", in Proceedinas of the Workshopon Low Temperiture Delectors for Nentrinos and Dark Malter, Ringberg Castle,Tegemsec, March 1213,1987,Pretzl,K. and Schmitz,N, and Stodolsky,L., Editors,(Springer Verlag, Berlin, Jeidelberg) p.113(1987).

12. H.H.,Stroke et al.,"Bolometers as Particle Spectrometers", IEEE Trius on Nuclear Science,NS 33, 759(1986).

N.,Coron et al.," Composite Bolometers as Spectrometers for X-Ray Astronomy", Second Intemational Technical
Symposium on Opdicil and Elecino Optical Applied Sciencess and Encinering, (1985).

N.,Coron c: al..Niturs.314.p.75(1985),

N.,Coron et al.,"Thenmal Spectroscopy' with Cooled CompositeBolometers and Measurement of $\mathrm{New}$ Phenomena".in Euceedings of VII Moriond Work shop Searches for New and Fxotic Phenomena (1987).

13. S.H.Moseley and D.,McCammon, Private Communication.

14. M.W.,Goodman and E.,Witten, "Detectahility of certain dirkmitter canditates", Phys, Rev, D31, p.3059)( (985).

I., Wasserman, Phys, Rev. D33, 2071(1986).

A.K..Drukier and K.,Freese and D.N.Spergel,"Defecting Cold Dark Matter Candidates", Bhus, Rev, W3,3, p.3495(1986).

15. L.,Gonzalez-Mestres and D.,Perret-Gallix,"Supurliested Superonducting Granules: $A$ Detector for Pantele Physies

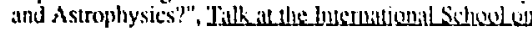
"Astro. Parlicle Phusics", LAPP. EXP 87-(1), (1987)

L.,Conzalez-Mestres and D.,Pertet-Gallix, "Denection of Magnetic Monopoles with Superles:led Type-1

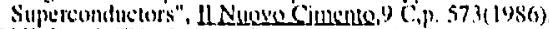

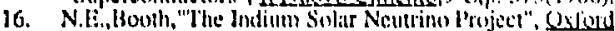
Luivorsiy lewpid, (1967).

17. G.,Waysiukl, "Solar Neutrino Indium Dolector Using

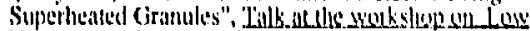

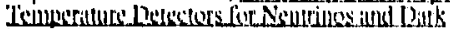

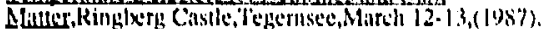

18. A, Drukier, l'tivale Communication.

19. 11. ,Bernas et al.,Wliss,Lell, 24A,p. $721(1067)$.

C.. Valctle, Ihs'sis, (1971).

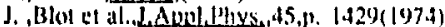

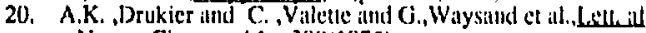
Nuovo Cimento, 14,p.301(1)(1975).

A.K.,Drukier and L.C.L., Yuan, Nuel. Jesir. Melle, 138, p.213(1976).

21. L.,Gonzalez-Mestres and D., Perret-Gallix., "New Results on the Basic Properties of Superheated Granules Deterturs", in

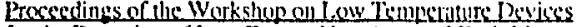

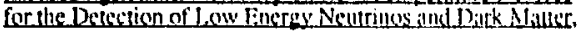
Ringberg Caslle (13avariai,LA1PP-IEXP-86-05, (1987).

22. K.,Pretzl et al.,"An Investigation of Superconducling Granules for a Low Line'gy Neutrino or Dark Matter Detector", in Procesdinas of uhe VII Moriond Workshop on "Senrches for New ind Fxodic Pluenomena" les Ares, France, Jan 24.31, 1987, (1987).

K.,Prelzl,"Investigation of Supercondtuting Jin Ciranules fora low-Energy Neutrino or Dark Matler Detectsr", in Procededings of the Worshop on low lempersilure Detectors for Neurinos iuld Dark Matuer. Ringlxils Castle, Tegernsee, Mitrch 12-13,1987, Jretzl,K and Sclinitz,N. and Sterdolsky,l.., Eiditors,(Springere-Verlig, Berlin Ileidelterg),p). 30(1987)

23. M.,Le Gros ct al., "Stpuid Delection of Superlieited Granules",in Procecedings of the Warkshop oul Low Teumeralure Delectors for Neutrinos and Dints Mallur, RingbergCastle,'Tegermsec, March 12-13,1987, Pretzl,K. and Schmitz,N, and Stodolsky,L., (SpringerVerlag, Berlin, Heidelberg) p. 37(1987).

24. O.,Liengrme, "VLSI Superconducting Particle Delectors",it Procedinas of the Workshon on Law 'Temperiture Desectors for Nuutrinos ind Dirk maller, (Springer-Verlag, Berlin,llcidelberg) p. 44(1987).

25. B.,Neuhauser and B.,Cibrera and C.J., Martoff et al.,"Phonon-Mediated Detection of Alpla Particles with Aluminum Transition Edge Sensors", in Proc. I 8 th Int.Conf.on Low Temperalure Physies, Kyoto, Ja. Journ. of Apllied Physics, 26, (1987).

26. B,,Neuhauscr et al.,IFEE Nuclear Symposium, San Francisco,(1987).

27. G.H., Wood and B.L., White,Apol.Phys.Lelt.15,p. 237(1969).

G.H.,Wood and B.L.,White,Cin. JPhys,51,p. 2032(197?)

28. M.,Kurakado and H., Mazaki, Phys. Rey,22,p. 168(1980) M, Kurakado and H.,Maziki, Nuclinsir.Mcih, $185, p .149$ (1981).

M.,Kurakado and H.,Mazaki,Nucl.Jnstr.Mell,,185,p. 141 (1981).

M.,Kurakado,LAopl,Phys,55, 3185(1984). 
29. A.,Barone er al.,in LT-15 Conference,(Elsevier Science, (1984).

A.,Brirone and ., de Stefano, and K.E.,Gray,Nucl.lnstr. Meth, A235,p. 254(1985).

A.,Barone et al,.Nucl.Instr. Meth, A234, 61(1985).

30. D., Twerenbold and A.,Zehnder and V.,Zacek, The IV international School of Physics of Exotic Atoms, Erice, Italy, 1984. Twerenbold,D.,"Giaever-type superconducting tunnelling junctions as high resolution $\mathrm{X}$ ray detectors", Eurephys. Lelt., 1, (1986).

D.,Twerenbold,Phys. Rev, B34,p. 7748(1986).

D.,Twerenbold and A.,Zehnder, JAnol.Phys,61,p.1 (1987).

31. H.,Krauss et al.,"High-Resolution X-Ray Detection with Superconducting Turne] Junctions", Europhys. Leth.1. p.161(1986).

F.V.,Feilitzsch et al,, "Catorinetric Detectors at Low

Temperatures", in Proceedines of the Workshop on Low

Temperature. Detectors for Neutrinos and Dark

Mlitter,Ringberg Castle, Tegernsee,March 12-13,

1987,Pretzl,K. and Schmitz,N and Stodolsky,L.

Editors,(Springer-Verlag, Berlin Huidelberg) p. 94(1987).

32. Th.,Peterreins and F, Proebst and $1 ., V$, Feilitzseh and H., Krituss,"Phonon Mediated Position Resolved Detection of Alpha larticies with Superconducting Tumnel Junctions" IFEF Nuclsar. Sumposium, San Francisco,(1987).

33. N.E.,Booth,"Quasiparticle trapping and the quasiprarticle multiplier", Ann Phys.Lall, 50,p. 293(1987).

34. J.C.,Mather,"Bolomeler Noise: Noneyuilibrium Theory", Appliesl Optics,21,p. 1125(1982).

J.C.,Mather,"Boloneters: ultimate sensitivity, optimization, and amplifier coupling", Applied Optics, 23, No4, p. 584(1984).

J.C.,Mather,"Electrical self-calibration of nonideal bolometers", Applied Optics, 23 Nol8,p. 3181 (1984).

S.H.,Moseley and J.C., Mather, and D.,

McCammon," Thermal Detectors as X-Ray Spectrometers", LAopl.Phys. 56(5),p. 1257(1984).

35. P..Richards and T.,Kenny and E.,Kreysa, Private Communication.

36. N.,Wang et al," "A 20mK Temperature sensor", IEEE Nuclear Science Symposium,San Francisco,(1987).

37. E.E.,Haller et al.,"NTD Germanium: A Novel Material For LowTemperature Bolometers", Liwrence Berkeley Jaboratory Preprint,LBL-14649(1985).

38. H.J.,Maris, "Design of Phonon Detectors for Neutrinos", Fifth Intemational Conference on Phonon Scattering in Condensed Malier, Urbana, Illinois, June 2-6,COO. 3130TC-29, (1986).

W.,Eisenmenger,Physical Acoustics XII,(Academic Press, New York, San Francisco,London) 79(1976).

J.P.,Wolfe,"Ballistic Heat Pulses in Crystals", Phys. Today, 44(1980).

39. B.,Neuhauser and B.,Cabrera et al.,"Acoustic Detection of Single Particles for Neutrino Experiments and Dark Matter Searches", 1986 Applied Superconductivity Conference, Baltimore, Maryland,(1986).

40. E.,Silver et al.,"Microcalorimeters for X Ray Spectroscopy",in Proceedinas of the IAUCollogium-102 UV and $X$ ray Spectroscony for Astronhysical and Laboratory plasnas, Beaulieu/Mer France,Sept 9.11,(1987).

41. T.O.,Niinikoski et al.,"Heal Capacity of a Silicon Calorimeter at Low Tempentures Measured by Alpha Particles", Europhys.Lett.,1,p. 499(1986).

T.O.,Niinikoski and A.,Rijltart,"Coherent Neutrino-Nucleus Elastic Scattering in Ultralow Temperalure CalorinetricDetectors", in Proceedings of the Workshop on Low Temperature Detecloors for Neuuninos and Dark Matter, Ringbergh Castle. Tegernsee,March 12 . 13,1987,Pretzl,K. and Schmitz,N. and Stodolsky,L., Editors,(Springer-Verlag, Berlin,Heidelberg) p. 135 (1987).

T.O.,Nïinikuski and A.,Rij̈lart,"Data Acquisition and Analysis of Calorimetric Signals", in Proceedings of the Workshep on Low Temperature Deteciors for Neutrinos and Dark Matier,Ringberg Casule,Tegemsec, March 1213,1987,Pretzl,K. and Schmitz,N, and Stodolsky,L., Editors,(Springer-Verlag, Berlin, Heidelberg) p. 143(1987).
42. R.E.,Lanou and H.J.,Maris and G.M.,Seidel,"The Use of Rotonsin Liquid Helium to Detect Neutrinos", in Proseedings ofthe Workshop on Low Temperature Detectors for Neutrinos and Dark Mauer,Ringberg Castle,Tegernsee,March 12-13,1987,Pretzl,K and Schmitz,N. and Stodolsky,L., Editors,(Springer-Verlig, Berlin,Heidelberg) p. 150(1987). 